\title{
LA PRODUCCIÓN INFORMAL DE VIVIENDAS: CASO MARACAIBO, VENEZUELA
}

\author{
(THE INFORMAL HOUSING PRODUCTION: THE MARACAIBO CASE, VENEZUELA)
}

\author{
Ignacio de Oteiza San José, Andrés Echeverría Villalobos y \\ Federico Arribas Zamora, Arquitectos
}

Fecha de recepción: 13-111-89

Universidad de Zulia. Facultad de Arquitectura. Maracaibo

(Venezuela).

A este trabajo le ha sido concedido el 1. ${ }^{\text {er }}$ Premio en "Investigación sobre vivienda". Banca Nacional de Ahorro y Préstamo (BANAP). Julio 1989 - Caracas - Venezuela.

\section{RESUMEN}

En la producción de viviendas en Maracaibo (Venezuela) existen dos sectores: el SECTOR FORMAL se refiere a la producción de la empresa privada más la producción estatal y el SECTOR INFORMAL que es la producción de viviendas en las áreas de barrios; la producción de este sector es mayor que la formal, llegando a ser el $60 \%$ de la población de Maracaibo. En Latinoamérica este fenómeno se presenta en la mayoría de las grandes ciudades.

Este trabajo analiza la vivienda desde el punto de vista físico, relacionando los aspectos constructivos con los socioeconómicos, de participación en la construcción y del financiamiento. Se establecieron 4 etapas de consolidación de la vivienda de producción informal, caracterizando cada una de las etapas de acuerdo a los promedios y porcentajes obtenidos. Es un trabajo analitico-descriptivo cuya finalidad es conocer los patrones de consolidación de estas viviendas, con el objeto de realizar recomendaciones para el proceso $y$ producción de la vivienda informal en Maracaibo.
SUMMARY

In housing production in Venezuela and particularly in Maracaibo, we can recognize two main sectors: the "formal" sector production carried out by private and national enterprises, and the "informal" sector, which produces houses in marginal areas and uncontrolled suburbs in town. The production in this sector has become larger than the formal one. In act, in Maracaibo more than $60 \%$ of population is living in these types of suburbs. These people have resolved their housing need accordingly to their low income and outside of offer sector of formal production.

This paper analyses the house from a physical point of view by studying the constructives components in relation to the socioeconomical aspects of the families and their direct participation in building and financing their house.

Four stages of the physical consolidation of housing in suburbs were distinguish. This contribution as an analytic description of the physical situation of housing in studied areas, concluded giving some recommendations for the improvement of the informal process of housing production in Maracaibo.

\section{MARACAIBO Y LAS ÁREAS DE BARRIOS}

Maracaibo, como segunda ciudad del pais, no escapa al problema general de la vivienda. Una de sus caracteristicas físicas es la gran proporción de áreas marginales en su periferia, siendo esta periferia más grande que la ciudad "formal". Sin embargo, tiene una característica especial diferente a lo que se observa en Caracas, ya que su geografía es principalmente plana, con una gran extensión, y llama la atención cómo estas zonas tienen una abundante vegetación, tapando en muchos casos las viviendas de los barrios, por lo que este problema pareciera de menor envergadura que el de la capital.
Podemos decir que los factores que agudizan el problema de la vivienda, a nivel nacional, están presentes en el problema habitacional de Maracaibo. Factores de tipo demográfico, junto a las migraciones y los factores politico-económicos son los determinantes de esta problemática.

Maracaibo ha tenido un crecimiento de población sumamente alto, pasando de 252.573 habitantes en el año 1950 a 1.179 .595 habitantes para el año 1988, lo que ha representado en los últimos 20 años un crecimiento de población interanual con un promedio del $3,7 \%$ 
Por supuesto, este incremento de población ha sido también determinado por las migraciones del campo a la ciudad, ya que en ella se dio una gran concentración de inversiones, actuando no sólo como centro de atracción para las migraciones rurales. Su auge económico de los años 60 y 70 fue un polo de atracción para los diferentes paises del Caribe y de América del Sur (en especial Colombia), quienes por la cercania de la frontera se establecieron en muchos casos de un modo ilegal, a veces transitorio, buscando una mayor es. tabilidad política y económica, y ubicándose en las áreas marginales, creando nuevos barrios o integrán. dose a los existentes.

Por esta razón, las áreas marginales de Maracaibo han sido engrosadas, no sólo por las migraciones nacionales (campo-ciudad), sino también por las migraciones extranjeras.

De los factores político-económicos podemos señalar que la política habitacional ha sido dirigida desde la capital con características semejantes, pero con menor nivel de actuación en la inversión que en el centro de poder, lo que en muchos casos de políticas de remodelación y consolidación de barrios, por parte del Estado, significó una menor atención a la población marginal que la realizada en Caracas.

En cuanto a lo económico podemos observar incompatibilidad entre la oferta y la demanda de vivienda, debido a la escasa capacidad de pago de la mayoria de la población, ubicada en la periferia, produciendo ellos mismos las viviendas que el sector formal no era capaz de ofrecrer (Gráfico 1).

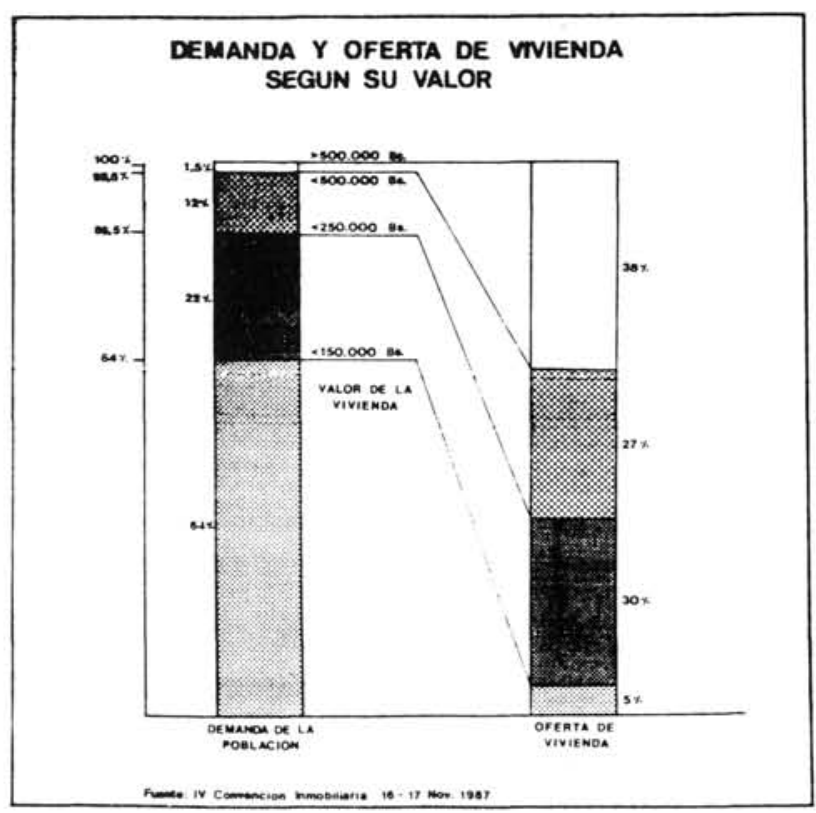

Gráfico 1

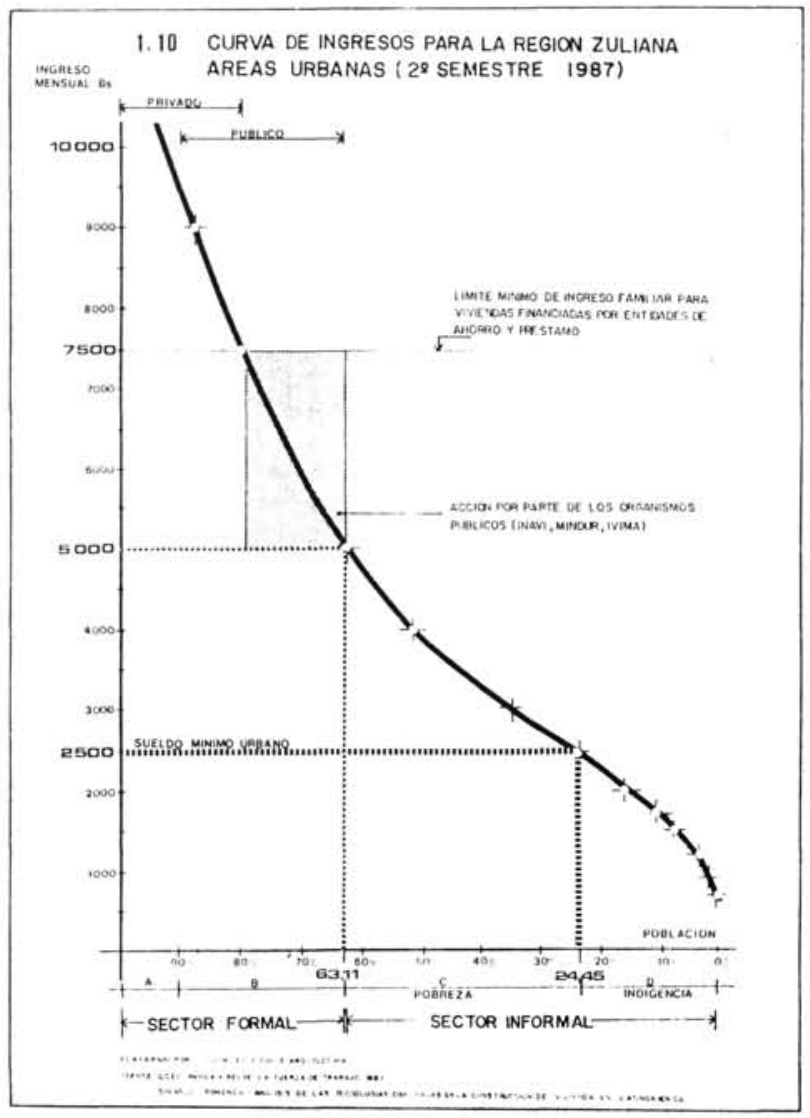

Gráfico 2

Analizando el gráfico 2, de ingreso mensual de la población urbana en el Zulia, observamos los dos sectores ya señalados de la producción de viviendas.

\section{EL SECTOR DE PRODUCCIÓN FORMAL}

Es aquel cuya población puede tener acceso a la vivien. da terminada. En éste observamos dos subsectores:

- El subsector "A", donde incluimos la producción del sector privado, cuya oferta de vivienda está dirigida a la población de mayores ingresos. Actualmente podemos ver, en Maracaibo, que la oferta mayoritaria de vivienda de este subsector está conformada por viviendas unifamiliares 0 apartamentos con costos sobre el millón de bolivares, lo que representa en muchos casos un valor sobre los $10.000 \mathrm{Bs} / \mathrm{m}^{2}$ para una población con la menor demanda real de vivienda, siendo la vivienda una inversión.

- El subsector "B", que representa aproximadamente un $30 \%$ de la población, que según su nivel de ingreso podria tener acceso a las ofertas de vivien. da producidas por el Estado, a las soluciones del

http://informesdelaconstruccion.revistas.csic.es 
INAVI, MINDUR, y otros organismos estatales o municipales. Sin embargo, en estos momentos este subsector " $B$ " se encuentra prácticamente paralizado, ya que hay muy poca oferta de viviendas de este tipo en Maracaibo.

\section{EL SECTOR DE PRODUCCION INFORMAL}

Comprende más del $60 \%$ de la población de Maracaibo; la de menores recursos, en situación de pobreza o indigencia. Es el sector que ha ido resolviendo el problema de la vivienda en correspondencia con la irregularidad de su ingreso, haciéndola a la medida de sus posibilidades; una construcción progresiva ocupando gran parte de las áreas de la ciudad.

\section{CRECIMIENTO DE LOS BARRIOS EN LA CIUDAD DE MARACAIBO}

Aunque los primeros asentamientos no controlados o barrios de Maracaibo los podemos ubicar a principios de este siglo (Paraiso y El Bajo en San Francisco 1904, Santa Lucia, etc.), este trabajo comprende solamente aquellos que fueron fundados dentro de los últimos treinta años (que corresponde al periodo democrático), por considerar que ha sido en estas últimas décadas cuando Maracaibo ha experimentado su mayor crecimiento y ha sufrido las mayores transformaciones a causa de estos asentamientos.

El análisis se basa en la información suministrada por FUNDACOMUN (principalmente), Concejo Municipal de Maracaibo, OMPU (Oficina Municipal de Planeamiento Urbano) y ENELVEN.

Observamos cómo Maracaibo, en el inicio de la democracia, sufrió un incremento muy grande de los barrios ya que, como se señaló anteriormente, se pasó de una política de tipo represivo a un dejar hacer con respecto a las áreas de los barrios. Durante los tres primeros periodos presidenciales democráticos ( 15 años) se duplicó el número de barrios de 69 a 139. Las políticas habitacionales fueron similares a las señaladas a nivel nacional: acciones en algunos casos de remodelación y equipamiento de barrios, sobre todo a los más consolidados (que correspondian generalmente a los de mayor tiempo de fundados). A finales de este período hubo una política agresiva de producción de viviendas de bajo costo (urbanizaciones populares) Ilegando a producir 10.442 viviendas el sector oficial entre 1969-1973 en los desarrollos habitacionales de San Francisco (2.066 viviendas), Cuatricentenario (1.786 viviendas) y San Jacinto (4.419 viviendas) como los más importantes.

Del año 1973 al 1978 aparecen 21 nuevos barrios. La po. litica habitacional ahora se caracteriza por la produc.

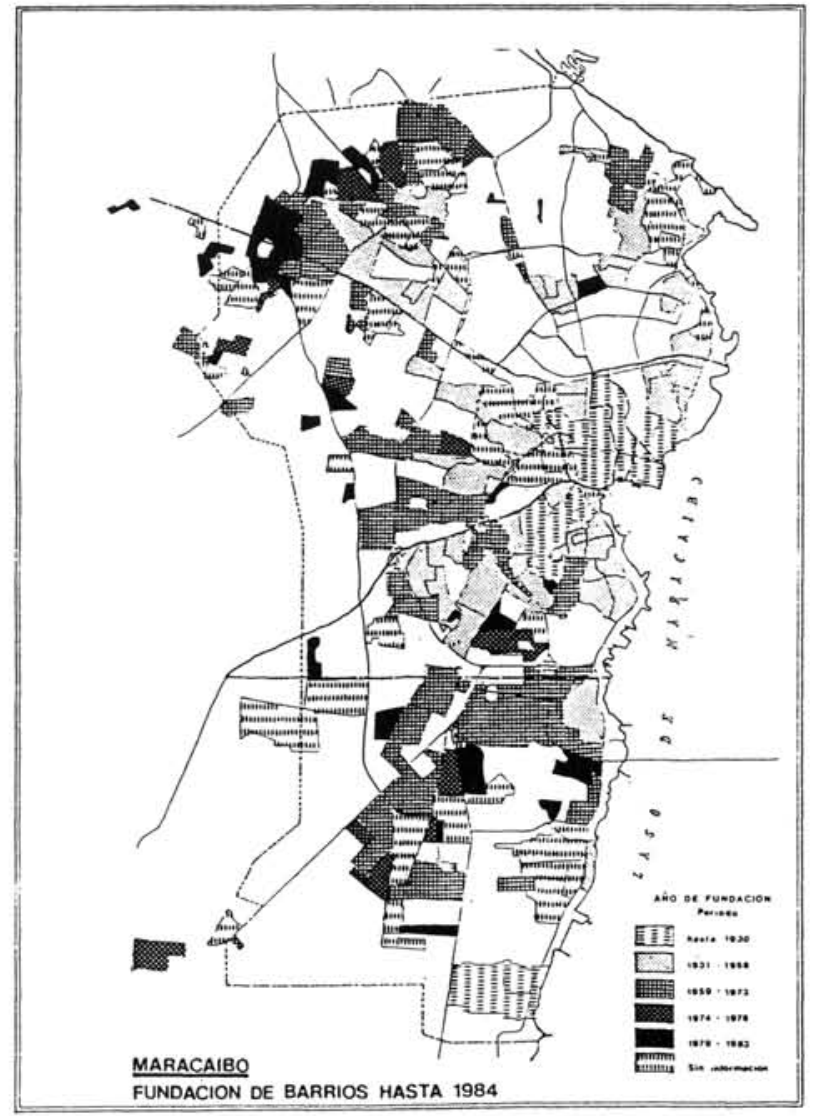

Gráfico 3

ción de viviendas terminadas con sistemas prefabricados importados, experimentando una baja considerable la producción de viviendas por el sector público totalizando tan sólo 2.478 viviendas, muchas de las cuales fueron desarrollos mixtos - sectores público y privado conjuntamente- (Gráfico 3).

En 1978 el 1. ${ }^{\text {er }}$ Inventario Nacional de Barrios establece para Maracaibo la cantidad de 134 barrios, que equivale a una población de 318.345 habitantes, es decir, el $40,1 \%$ del total de ese año.

El crecimiento de la cantidad de barrios en este quinquenio fue superior al anterior, llegando a 206 el total en Maracaibo.

En 1985 FUNDACOMUN realiza el $2 .^{\circ}$ Inventario Nacional de Barrios, determinando un número total de 168 barrios, con una población asentada en estas áreas de 579.362 habitantes que equivale al $54,16 \%$ de la población total de Maracaibo. (Gráfico 4).

La mayoría de los barrios en Maracaibo están concentrados en los municipios Coquivacoa, San Francisco, Cacique Mara y Cristo de Aranza. Son también los municipios más grandes de la ciudad y en los que hemos hecho énfasis para nuestro estudio. 


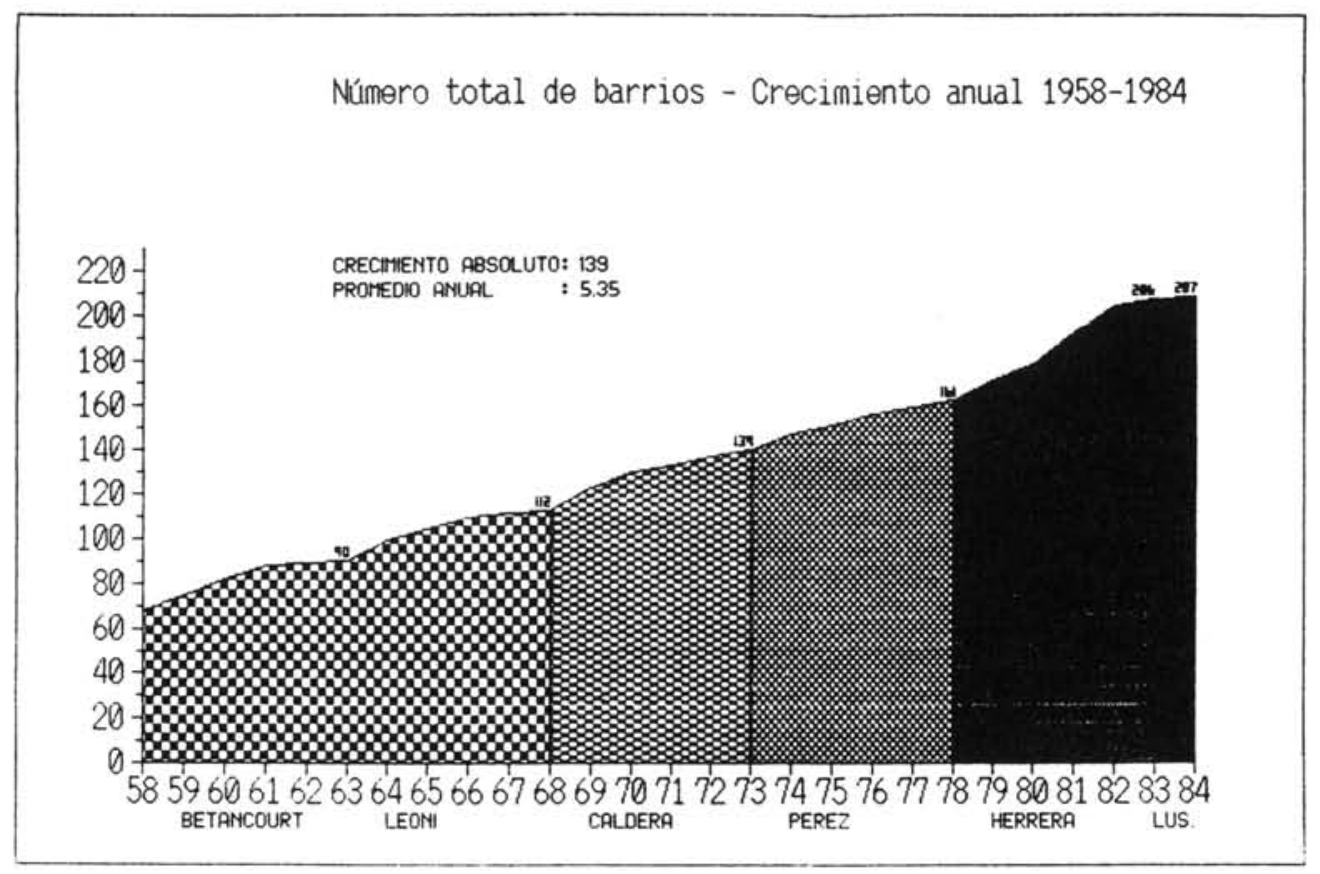

Gráfico 4

La superficie total de Maracaibo dentro del perimetro urbano, que incluye la expansión de 8.052 Has., en 1985, es de 22.545 Has. El $41 \%$ de esta superficie está ocupada por barrios en diferentes estados de consolida-

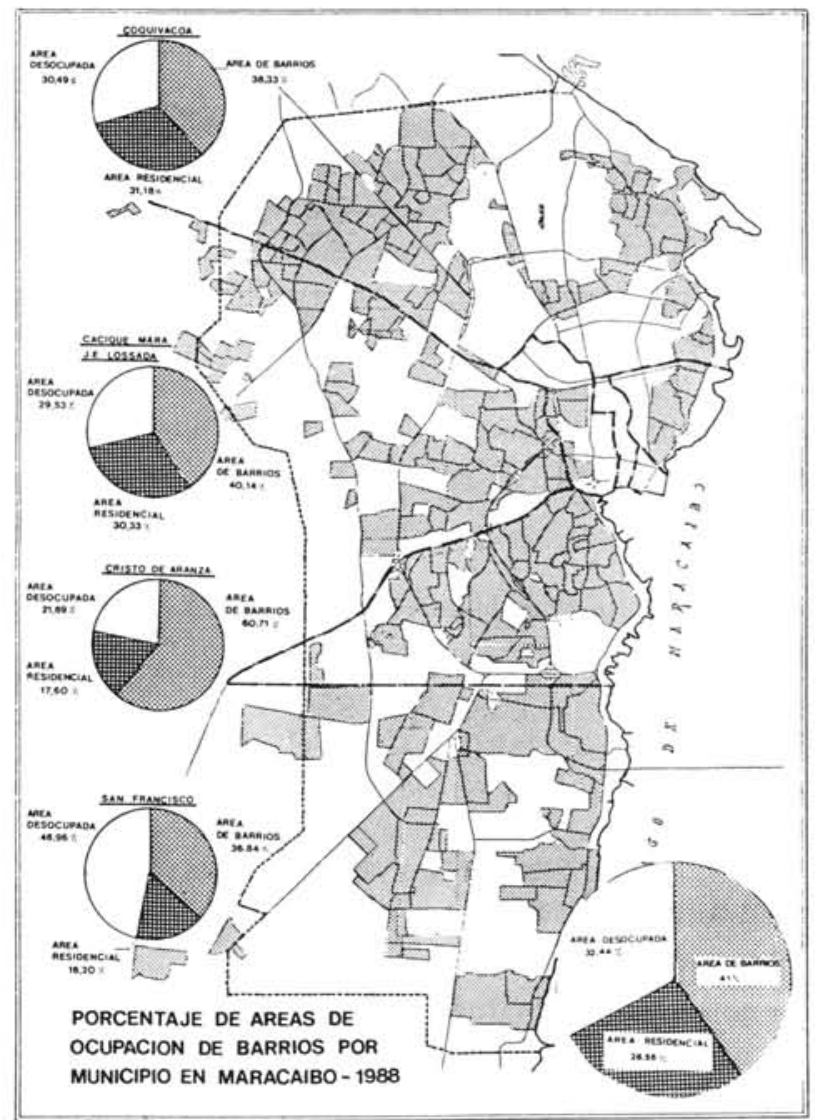

Gráfico 5.-Área desocupada, $7.411 \mathrm{Ha}$. Área de barrios, 9.147 Ha. Área residencial, $5.987 \mathrm{Ha}$. Área total de Maracaibo, $22.545 \mathrm{Ha}$. ción. Si no tomamos en cuenta las $7.411,30 \mathrm{Has}^{2}$ de área desocupada, esta cifra alcanza el $60 \%$. Esto significa que las viviendas ubicadas en el $60 \%$ del área ocupada de Maracaibo han sido producidas por el sector informal.

Antes del año 1985, cuando entra en vigencia el nuevo Plan Rector de la ciudad de Maracaibo, el perimetro urbano encerraba aproximadamente $11.000 \mathrm{Has}$. y el área de barrios, para esa época, representaba el $70 \%$ del área ocupada (Gráfico 5).

\section{PATRONES DE DESARROLLO DE LA VIVIENDA INFORMAL EN MARACAIBO}

El objetivo principal de la investigación es identificar las tipologias de organización espacial y los componentes constructivos de la vivienda de producción informal, analizando las mismas y determinando diferentes etapas de consolidación.

Cada vivienda es respuesta a una necesidad y a las posibilidades de los miembros que la ocupan. Entendemos que cada una de ellas responde a un proceso evolutivo propio y dinámico, de acuerdo a los procesos mismos de la familia, a su crecimiento, a sus posibilidades económicas en el tiempo y a sus intereses en general. Por estas razones, la variable de años de fundación de la vivienda es determinante. Sin embargo, consideramos que, analizando todas las variables que se indican en la encuesta y relacionándolas entre sí, podemos determinar patrones comunes para grupos de viviendas que nos indican la etapa de consolidación 
en que se encuentra cada una de ellas, asi como algunas de las características comunes de sus habitantes. Estos patrones que describen cada etapa deben tomarse como una generalización, ya que pormenorizan las caracteristicas de la mayoria de las viviendas, encontrándose algunos casos, como se observa en los listados anexos, que presentan algún aspecto diferente al grupo al que, a nuestro juicio, pertenecen.

En general, se establecen los patrones según cada uno de los aspectos de la encuesta. En la primera parte de este trabajo analizamos y comparamos los aspectos en todas las etapas, dando una visión global de la vivienda de producción informal en Maracaibo. En la segunda parte, señalamos los patrones que determinan cada una de las etapas.

\section{TIPOLOGIAS DE VIVIENDA}

Una vez realizadas las 207 encuestas, nos encontramos con una gran variedad de soluciones de vivienda en los barrios donde se realizó la encuesta. Se trata, en esta etapa de la investigación, de determinar tipologías de vivienda con énfasis en las características de los componentes constructivos.

En un principio identificamos tres grandes grupos según el estado de consolidación de la vivienda. En los extremos teniamos un grupo de viviendas encuestadas que se caracterizaba, en líneas generales, por la utilización de materiales de desecho para los cerramientos y la cubierta, a la que denominamos VIVIENDA FORMATIVA, y otro grupo que presentaba materiales perdurables en cerramientos, piso y cubierta, con acabados internos y externos, a la que denominamos VIVIENDA TERMINADA. El que una vivienda perteneciera a la clasificación de terminada no significaba necesariamente que la vivienda no podia experimentar futuras transformaciones o crecimiento, sino que su estado de consolidación física (calidad de los materiales, acabados y sistemas constructivos) habia alcanzado un nivel que consideramos satisfactorio para este tipo de viviendas.

En el medio estaba un grupo que representaba la transición entre los dos grupos anteriores, mostrando una amplia gama de posibilidades. En este grupo central, el más vasto de todos, se podian encontrar desde viviendas con un porcentaje bajo de utilización de materiales de desecho hasta casos con materiales perdurables en su totalidad y una baja presencia de acabados, es decir, muy cercano a un extremo y muy alejado del otro. Por esta razón se decidió subdividirlo en dos, cuyas viviendas representaban las etapas que dimos en llamar DE DESARROLLO (posterior a la FORMATIVA) y DE CONSOLIDACION (anterior a la TERMINADA).
De esta manera nuestra clasificación de las etapas de consolidación física de la vivienda quedó establecida asi:

\section{Vivienda en etapa formativa.}

\section{Vivienda en etapa de desarrollo.}

\section{Vivienda en etapa de consolidación.}

\section{Vivienda terminada.}

Para esta clasificación se tomaron en cuenta únicamente criterios constructivos, y sólo aquellos que sirvieran para mostrar lo más objetivamente posible las caracteristicas físicas de la vivienda. Todas las variables que intervienen en la definición de las etapas de consolidación se indagarían en la encuesta, y una vez determinada la etapa a la que pertenecen las viviendas, se procedería a cruzar variables para encontrar una caracterización de cada etapa en los otros aspectos (socio-económicos, de financiamiento, de construcción) e identificar una línea evolutiva.

A continuación se enumeran las características que deben presentar las viviendas de cada etapa para ser clasificadas como tales.

\section{Etapa formativa}

\section{A) Estructura:}

- Columnas (tipo horcones) y vigas de madera o de metal reciclados.

- No existen muros de carga.

- No hay fundaciones; las columnas apoyan directamente en el piso. Puede haber un piso de hormigón que ayuda a apoyar las columnas.

- La cubierta está sostenida por un entramado de madera o de metal con las mismas caracteristicas de las columnas (material reciclado) unidos entre si de forma provisional (clavos, amarres de alambre, etcétera).

- La cubierta puede presentar piedras y cauchos sobre ella como pesos para ayudar a fijarla contra los vientos fuertes.

- La cubierta se apoya en los cerramientos directamente. Las luces de las vigas y entramados son pequeñas (no mayor de $2,44 \mathrm{~m}$, el ancho estándar de una lámina).

\section{B) Cerramientos y Cubierta:}

- Los cerramientos exteriores son de material de desecho (cartón, cartón piedra, madera reciclada de encofrados y/o embalajes, chapas, latas extendidas, avisos, plásticos, etcétera).

- Los cerramientos interiores, de haberlos, han de ser de telas o de materiales similares a los exteriores. 
C) Acabados:

- No hay acabados. El piso puede ser de tierra, de suelo cemento o una base de piso muy rudimentaria.

\section{Etapa de desarrollo}

A) Estructura:

- Columnas de madera, hormigón o metálicas o, en ausencia de éstas, muros de carga de bloques de arcilla o cemento.

- Pueden existir o no elementos de refuerzo vertical y horizontal para los muros de carga.

- Fundaciones o base de pavimento donde se apoyan los muros o las columnas.

- Combinación de materiales perdurables o definitivos en algunas partes de la vivienda con otros de desecho propios de la etapa anterior.

B) Cerramientos y cubierta:

- Bloques de arcilla o cemento en los cerramientos exteriores e interiores.

- Cubierta de láminas metálicas.

- Combinación de materiales de desecho y definitivos.

C) Acabados:

- Ausencia de frisos exteriores e interiores a excepción (no necesaria) de la fachada principal.

- Parte interna de la cubierta a la vista.

- Pisos de cemento rústico o requemado.

D) Otras consideraciones:

- Pertenecerán a este grupo todas aquellas vivien. das que presenten combinación de sistemas constructivos y materiales transitorios y de desecho con otros perdurables y definitivos, a menos que uno de ambos esté presente en una proporción tan baja (se estableció como referencia un $10 \%$ ) o tan alta (se estableció un $90 \%$ ) que amerite pertenecer a clasificación de consolida. ción mayor o menor, según sea el caso.

- El estado de consolidación de los servicios exentos se tomará en cuenta igualmente, debiendo existir ya alguna pieza sanitaria en esta etapa.

- Los vanos para las ventanas deben estar definidos, asi estén provisionalmente tapados (con bloques cruzados u otro material).

\section{Etapa de consolidación}

A) Estructura:

- Columnas de madera, acero (no reciclados) u hormigón.
- Pueden existir muros de carga de bloques, adobes u hormigón en vez, o a la vez, de las columnas (combinado).

- Los muros de carga pueden presentar refuerzos.

- Entramado de acero, madera o ambos (no reciclados) para sostener la cubierta, si ésta es de láminas.

- Puede existir otro tipo de cubiertas, como losas macizas, nervadas, de bovedillas u otras, en partes o toda la casa.

B) Cerramientos:

- Los cerramientos exteriores e interiores pueden ser de bloques de arcilla o cemento, u otros materiales perdurables.

- Deben prevalecer en general los materiales perdurables y, en caso de existir algunos de desecho, no deberán exceder del $10 \%$ de la vivienda.

C) Acabados:

- Ausencia de frisos en los cerramientos exteriores, a excepción tal vez de la fachada principal, porche y alguna que otra pared.

- Presencia de frisos u otros acabados en los cerramientos interiores en gran proporción.

- Piso de cemento requemado como mínimo. Puede tener algún tipo de acabado (vinil, mosaico, granito, cerámica, etcétera).

- La parte interna de la cubierta está a la vista, por lo general.

D) Otras consideraciones:

- Deben existir las piezas sanitarias (inodoros, lavamanos y ducha).

- Pueden estar presentes los acabados en piso, cerramientos y techo, siempre y cuando éstos no alcancen la totalidad.

\section{Etapa terminada}

A) Estructura (igual a la Etapa de consolidación).

B) Cerramientos (igual a la Etapa de consolidación).

C) Acabados:

- Los cerramientos exteriores e interiores deben presentar acabados en su totalidad (friso, cerámica o lo que sea).

- En el caso de viviendas con cerramientos de bloques de cemento, se considerará acabado con la pintura sobre el bloque.

- El techo puede quedar a la vista, si es de láminas, o bien presentar cielo raso. Si es de placa, deberá estar debidamente frisada.

- Piso de cemento requemado en buen estado o con algún tipo de acabado sobre él (vinil, cerámica, mosaico, granito). 


\begin{tabular}{|c|c|c|c|c|c|c|c|c|c|c|c|}
\hline MUNICIPIO & TOTAL & cooui & $\angle A C O A$ & CACIOUE & MARA & J.E.LO & SSADA & C. DE & ARANZA & SAN FRA & ANCISCO \\
\hline FORMATIVA & 53 & 29 & 54.7 & 9 & 17 & 1 & 10 & 12 & 32.6 & 2 & 3.77 \\
\hline DESARROLLO & 53 & 27 & 51 & 5 & 9 & 7 & 13 & 9 & 13 & 4 & 2.85 \\
\hline CONSOLIDADA & 36 & 13 & 38 & 2 & 56 & 4 & $1 t$ & 16 & 44 & 1 & 2.78 \\
\hline TERMINADA & 65 & 11 & 17 & 14 & 22 & 9 & 13 & 31 & A7 & - & 0 \\
\hline TOTALES & 200 & \$0 & 38.05 & 30 & 14,40 & 21 & 20.44 & 31. & 34.20 & 8 & 14,100 \\
\hline
\end{tabular}

Gráfico 6

D) Otras consideraciones:

- Presencia de acabados en puertas y ventanas con materiales definitivos.

- Todas las piezas sanitarias presentes.

- Instalaciones embutidas en las paredes.

\section{COMPARACIÓN DESCRIPTIVA DE LOS DIFERENTES ASPECTOS EN LAS ETAPAS DE CONSOLIDACIÓN}

Se trata de mostrar en esta parte las caracteristicas generales de las viviendas de los barrios según la etapa de consolidación en que se encuentren, comparando de una manera descriptiva cada uno de los aspectos.

\section{INFORMACIÓN GENERAL}

En la relación entre las etapas de consolidación y la ubicación en los diferentes Municipios, observamos cómo en el Municipio Coquivacoa (norte de Maracaibo) está el mayor porcentaje de viviendas en ETAPA FORMATIVA (invasiones recientes) y por el contrario, en el Municipio San Francisco (sur de la ciudad) el porcentaje de viviendas en las etapas más consolidadas (EN CONSOLIDACIÓN y TERMINADA) se hace mayor (invasiones más antiguas). Ver gráfico 6 .

\section{ASPECTOS SOCIO-ECONÓMICOS DE LAS FAMILIAS}

\section{Tamaño de la familia}

El número de habitantes de las viviendas de los barrios va creciendo a medida que la vivienda aumenta su grado de consolidación.

En la mayoria de los casos $(90,02 \%)$ una sola familia habita en cada vivienda, registrándose sin embargo algunos casos poco frecuentes de dos o más familias por unidad. Estos casos se presentan en la última etapa de VIVIENDA TERMINADA (12,31\%). Ver gráfico 7.
NÚMERO DE HABITANTES DE LA VIVIENDA POR ETAPA

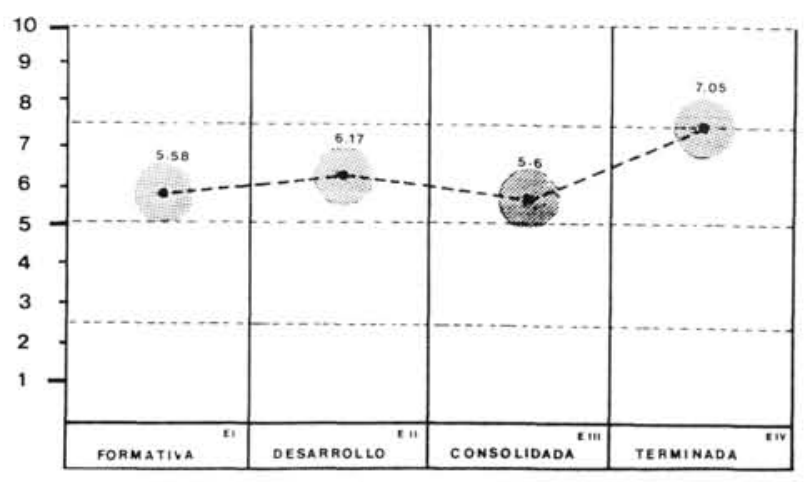

Gráfico 7

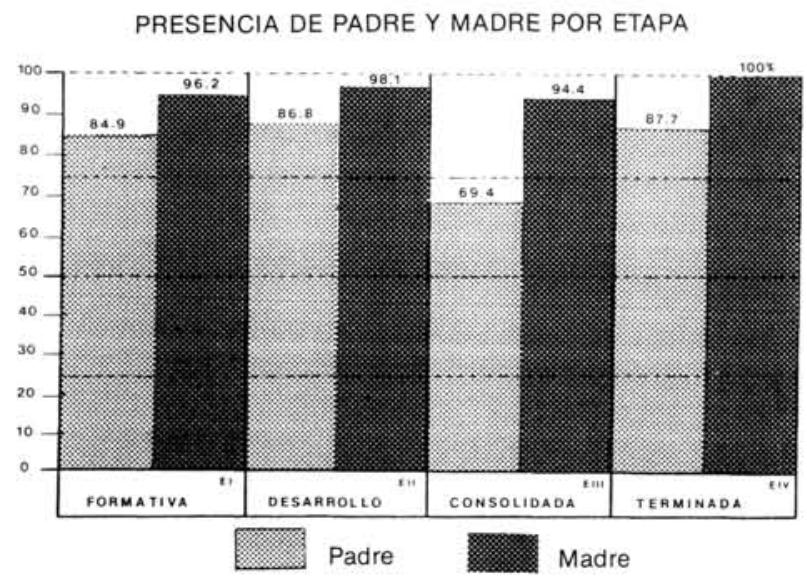

Gráfico 8

\section{Composición familiar}

En general se observa la presencia del padre y la madre en las diferentes etapas de la vivienda, siendo la presencia de la madre mayor en todas las etapas y en la casi totalidad $(97,17 \%)$ de las viviendas encuestadas. (Gráfico 8). 
TIPO DE FAMILIA POR ETAPA

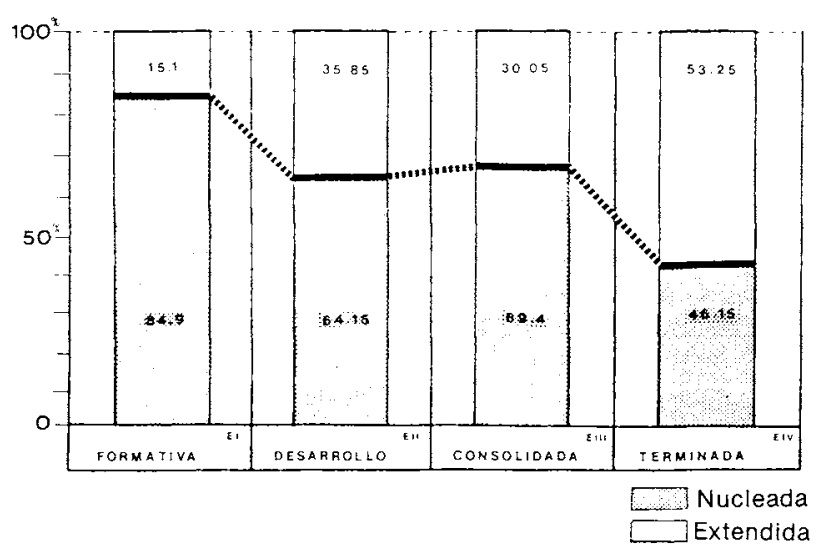

Gráfico 9
El promedio de hijos en las familias va aumentando con la consolidación de la vivienda, pasando de 3,26 hijos en la primera etapa a 3,71 en la cuarta.

\section{Tipo de familia}

Además de la familia básica (padres e hijos), se observa cómo en la primera etapa, en la mayoría de las viviendas, no habitan otros miembros; sin embargo, a medida que la consolidación avanza, se incorporan otros miembros a la familia: nietos, hijos politicos, abuelos y otros parientes. Significa esto que la familia en la primera etapa es mayoritariamente nuclear (familia básica: padres e hijos); en la segunda y tercera etapas siguen predominando las familias de tipo nuclear, aunque en menor proporción, y en la última etapa predominan las familias extendidas (familia básica más otros parientes). Ver gráfico 9 .

\section{Edad de los miembros de la familia}

El promedio de edad de los padres va aumentando a medida que la etapa de consolidación es más avanzada.

En la ETAPA FORMATIVA la mayoría de los hijos (70\%) es menor de 12 años y está en edad escolar; en la última etapa (TERMINADA) la mayor parte de los hijos tiene más de 12 años (73\%), predominando los mayores de 18 años $(54,4 \%)$. Ver gráfico 10 .

\section{Número de miembros del hogar que trabajan}

A medida que la etapa de consolidación es mayor el número de miembros que trabaja y aportan al hogar tambièn es mayor. Esto es razonable ya que tanto el nú. mero de miembros en la familia como la edad de los hijos va aumentando según la etapa de consolidación. (Gráfico 11).

\section{Actividad de los miembros de la vivienda que trabajan}

La actividad de los miembros que habitan las viviendas de los barrios es muy variada, por lo cual, además de diferenciar las ocupaciones, se hizo necesario analizar las de cada uno de los integrantes de la familia.

Padre: se determinó como actividad más frecuente la construcción, observándose que en la ETAPA FORMATIVA más de una cuarta parte de los encuestados $(26,41 \%)$ se dedica a esta actividad. En las etapas posteriores de consolidación, la cantidad de padres dedicados a la construcción se reduce, aunque sigue siendo la actividad primordial (prom. 22,03\%). 


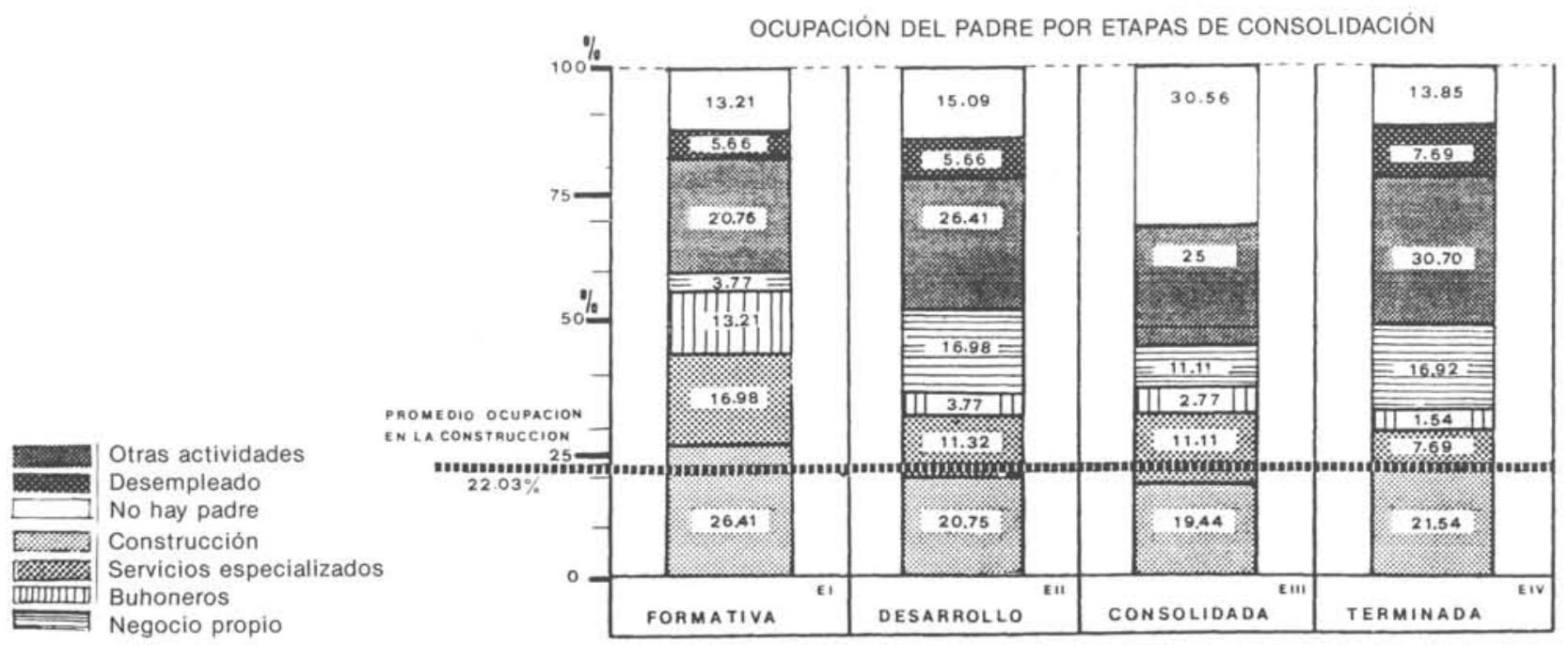

Gráfico 12

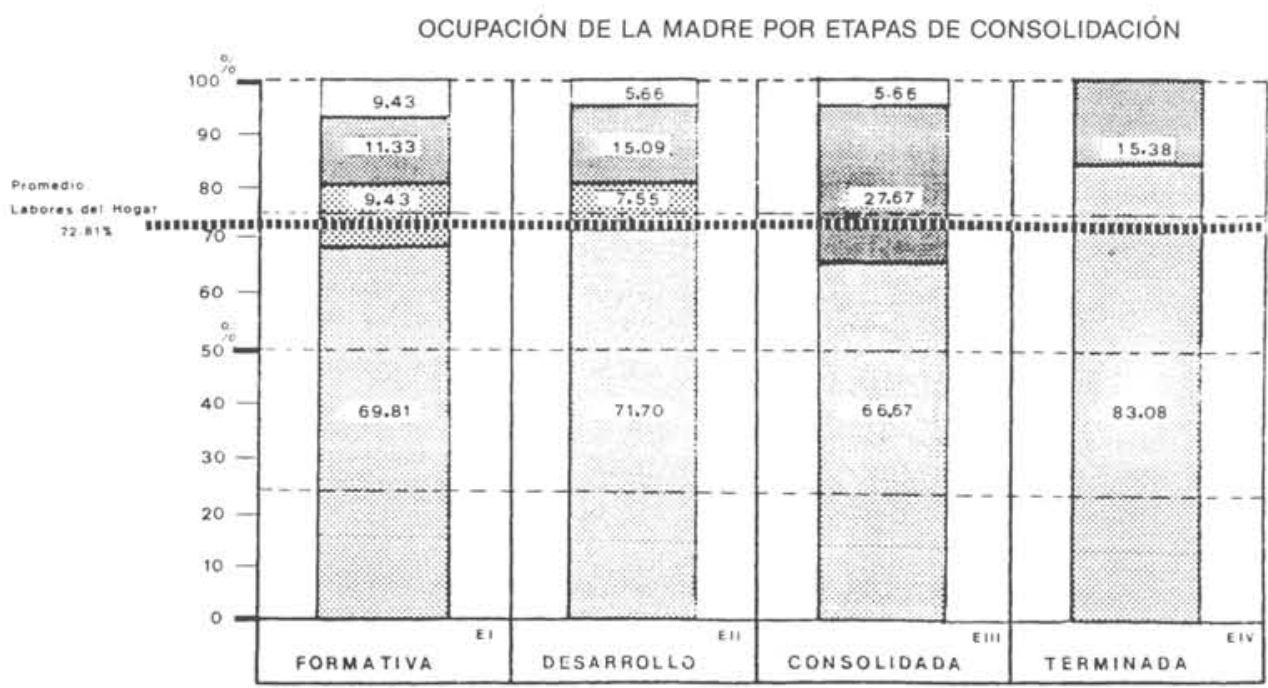

Gráfico 13

En la primera etapa se observa un alto porcentaje de buhoneros $(13,21 \%$ ) y de padres dedicados a servicios especializados diferentes a la actividad de la construcción $(16,98 \%)$. En la última etapa, cabe destacar el aumento de los padres con negocio propio (16,92\%). $\mathrm{El}$ desempleo se mantiene relativamente uniforme en las diferentes etapas, y en todas menor al 8\%. (Gráfico 12).

Madre: en general se dedica a labores del hogar en todas las etapas de consolidación, siendo en la primera etapa donde se encuentra el mayor porcentaje de madres con otra ocupación fuera del hogar $(20,76 \%)$, trabajando la mayoría de éstas como servicio doméstico $(9,43 \%)$. Ver gráfico 13 .
Hijos: en la primera etapa son, en su mayoria, menores de edad y no se tomó en cuenta su ocupación. En las etapas de mayor consolidación aumenta la cantidad de hijos con alguna ocupación, y en algunos casos se integran parientes con algún tipo de trabajo.

\section{Ingreso mensual familiar}

Durante las tres primeras etapas de la vivienda los ingresos familiares no sobrepasan los niveles mínimos, lo que significa que estas familias están dentro del nivel de pobreza, observándose un incremento poco sustancial de los ingresos aun entre las etapas de consolidación más alejadas. Sólo en la última etapa la mayoría de estas familias (70\%) sobrepasa los niveles de pobreza. (Gráficos 14 y 15). 
INGRESO MENSUAL FAMILIAR (Promedio por etapas)

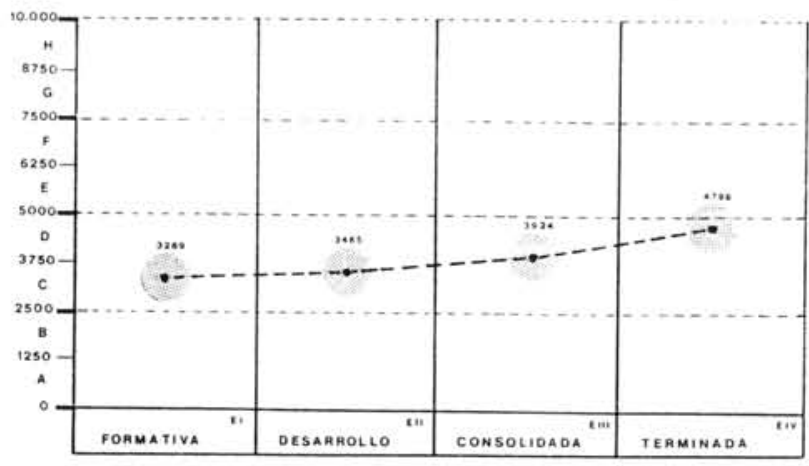

Gráfico 14

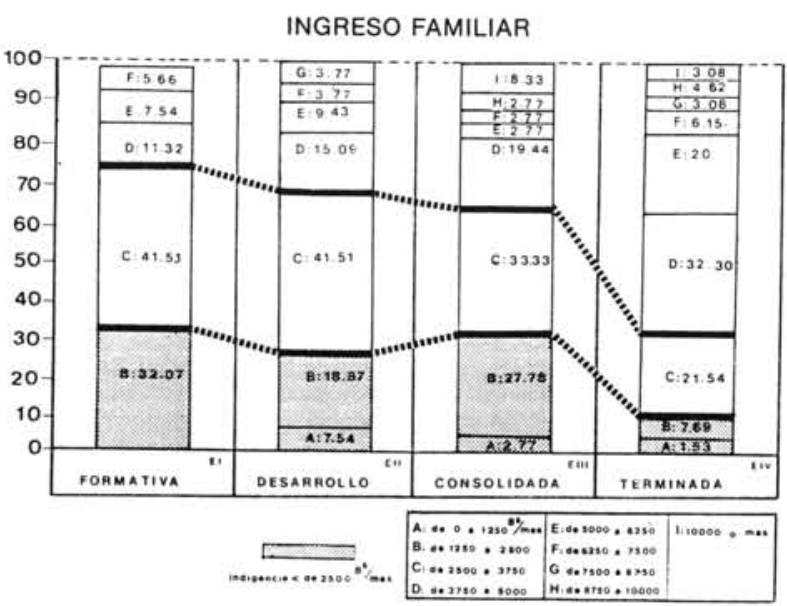

Gráfico 15

\section{ASPECTOS FISICOS}

\section{Características del lote}

Más del $90 \%$ de las viviendas encuestadas, en cada una de las etapas, se encuentra ubicado en terrenos planos y en general aptos para la construcción de viviendas. En la ETAPA FORMATIVA casi el $6 \%$ se encuentra ubicado en cauces de quebradas o terrenos anegadizos; este porcentaje va disminuyendo a medida que la consolidación aumenta, existiendo sin embargo un 3\% de las viviendas terminadas en terrenos no recomendables para la construcción. No se realizaron estudios geofísicos del terreno, solamente se tomaron en cuenta los aspectos hidrológicos (cauces de quebradas o terrenos anegadizos) y morfológicos (en pendiente o planos) para determinar si los terrenos son aptos o no.

El promedio de las dimensiones del terreno nos muetra que en las etapas de mayor consolidación el terreno es más grande; esto no significa que aumenten las dimensiones del lote a medida que el proceso avanza, sino que en las invasiones de terrenos más antiguas el lote era generalmente mayor.
Debemos señalar que hay casos excepcionales en los que el tamaño de la parcela se aleja mucho del promedio general. En algunos casos tienen características de terrenos de tipo rural, es decir, muy grandes y fuera del límite urbano, por lo menos hasta hace tres años (la nueva delimitación urbana data de 1985). Ver gráfico 16.

El porcentaje de área ocupada de terreno por la construcción es muy bajo en la generalidad de los casos ( $32,4 \%$ promedio en la etapa TERMINADA), aun cuando se observa un ascenso del mismo con la consolidación de la vivienda. Este ascenso debería ser mayor debido a que las viviendas crecen en tamaño con la consolidación (como veremos más adelante), pero no es asi porque los terrenos también son mayores, como acabamos de señalar. (Gráfico 17).

\section{Tenencia del terreno}

El terreno en la mayoria de las etapas es invadido (característica típica de la vivienda de producción informal) predominando la invasión a terrenos municipales o de la nación. Esto parece indicar que la situación de ilegalidad no es un impedimento para que se consolide la vivienda. En el gráfico 18 se observa cómo, aun

SUPERFICIE DEL TERRENO Área y Dimensiones* (Promedio por etapas)

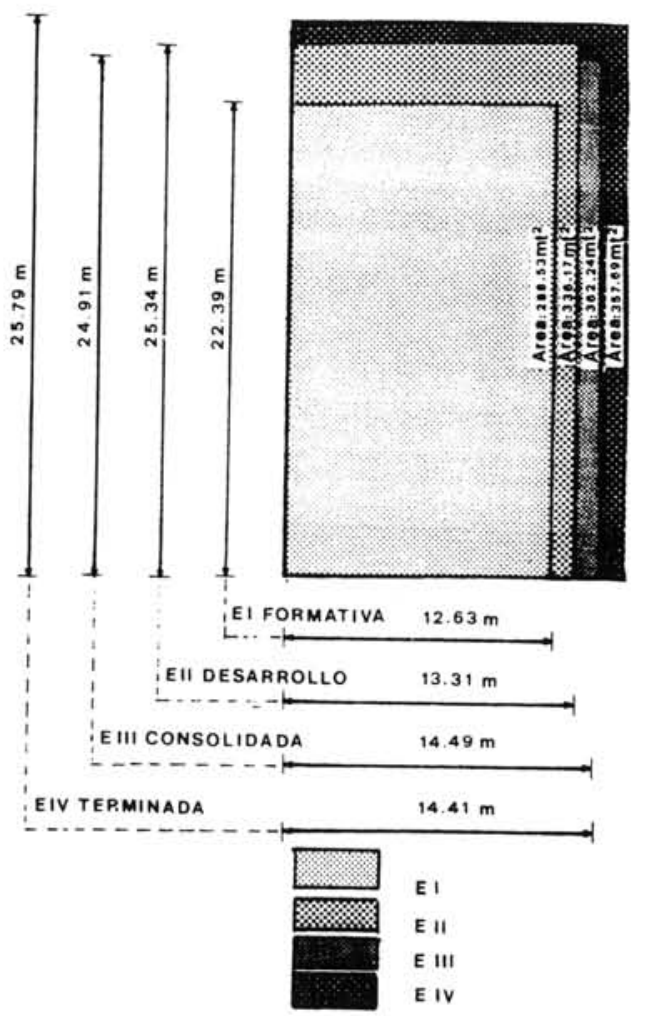

- La superficie del terreno corresponde a los terrenos de un área menor de $600 \mathrm{~m}^{2}$

Gráfico 16 
SUPERFICIE OCUPADA DEL TERRENO POR ETAPA (\%)

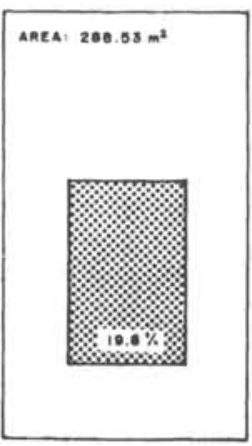

FORMATIVA

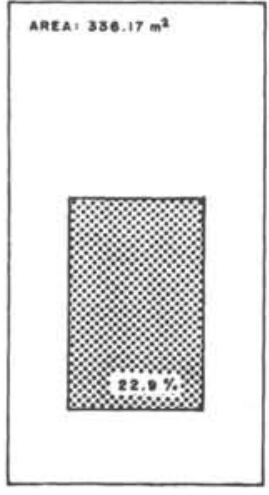

DE DESARROLLO

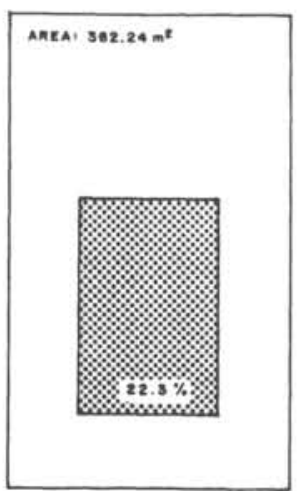

DE CONSOLIDACION

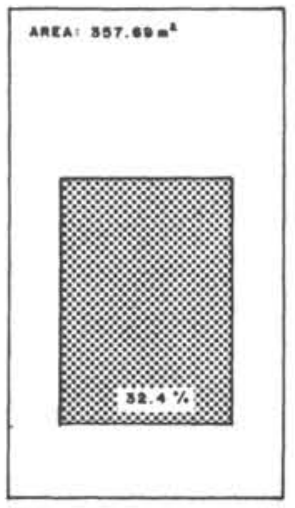

TERMINADA

Gráfico 17

PROPIEDAD DEL TERRENO POR ETAPA DE CONSOLIDACIÓN

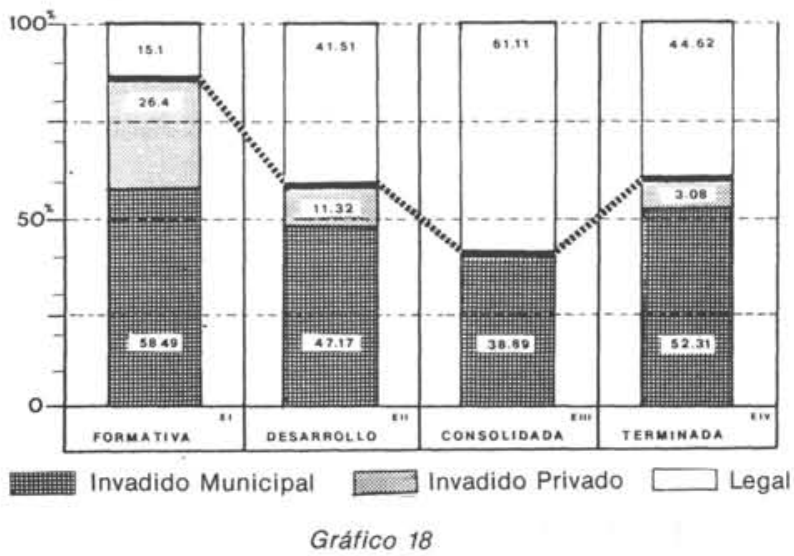

en la ETAPA TERMINADA, más de la mitad de las viviendas siguen estando en terrenos invadidos.

\section{Número de pisos}

La totalidad, menos una (206) de las viviendas encuestadas, son de un solo piso. Esto indica que la consolidación no está asociada al crecimeinto vertical, tal vez por el gran espacio libre de terreno para crecer de que se dispone (promedio de un 75,7\% libre).

\section{Años de la vivienda}

Este es el aspecto más importante de la consolidación de la vivienda; a medida que la vivienda tiene más años el grado de consolidación es mayor. La consolidación es un proceso evolutivo, por tanto se va dando a través del tiempo. (Gráfico 19).

El promedio pasa de siete años y medio para la ETAPA FORMATIVA, a casi dieciocho para alcanzar su termi-
PROMEDIO DE AÑOS POR ETAPA EN LA CONSOLIDACION DE LA VIVIENDA

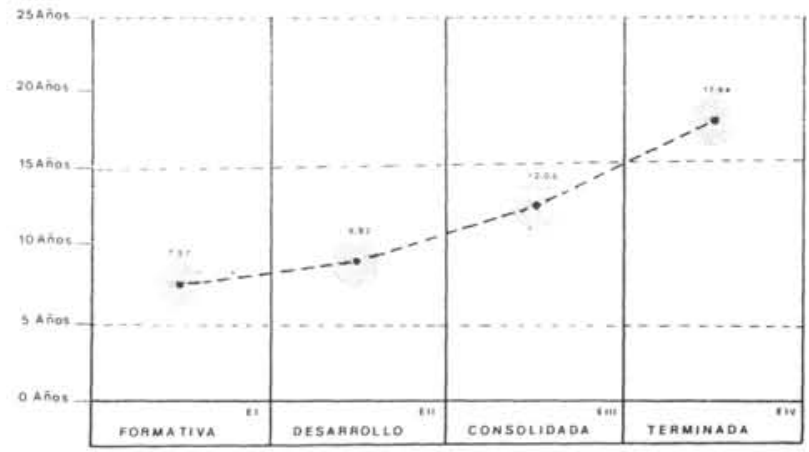

Gráfico 19

nación. Por supuesto, éstas son cifras promedio, pero se pueden encontrar algunas viviendas TERMINADAS con sólo 5 años de fundadas, asi como otras con 20 años que aún permanecen en la primera etapa. Para comprender este fenómeno, probablemente haya que estudiar las variables socio-económicas de la familia y hasta la situación del país, pues muchas de las respuestas están allí. Es importante volver a indicar que el análisis que hacemos es un corte en el tiempo y no un seguimiento del proceso evolutivo de cada caso.

\section{Propiedad de la vivienda}

Es una característica común en todas y cada una de las etapas que la vivienda sea propia y pagada. Alrededor del $90 \%$ de las viviendas están en esta situación. Un porcentaje que no sobrepasa el $10 \%$ - a excepción de la ETAPA DE CONSOLIDACION con un $14 \%$ - son viviendas propias que aún se están pagando, y un porcentaje aún menor (despreciable) corresponde a las viviendas alquiladas. 
SERVICIOS PÜBLICOS DISPONIBLES POR ETAPA DE CONSOLIDACIÓN

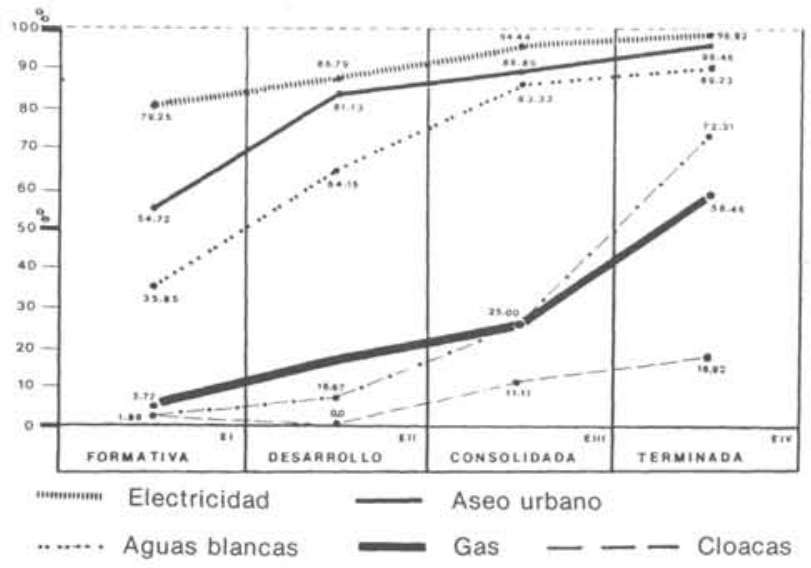

Gráfico 20

PROMEDIO POR ETAPAS DE ESPACIOS EN LA VIVIENDA - Incluye sanitario separado o no

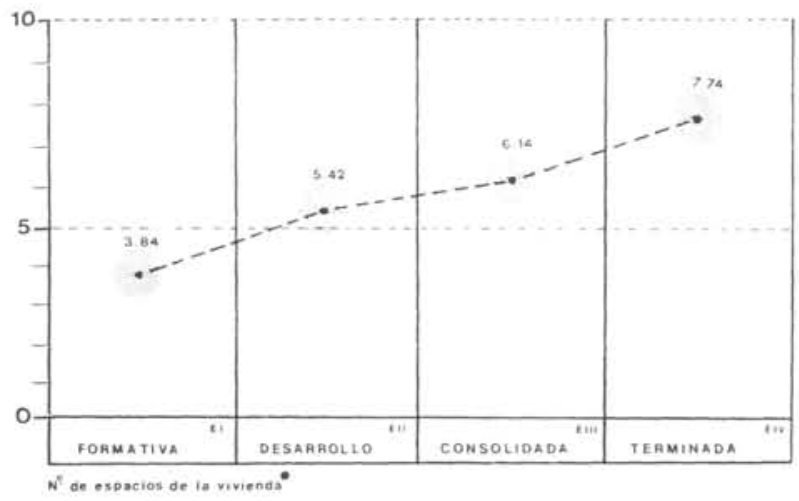

Gráfico 21

AREA PROMEDIO DE LA VIVIENDA POR ETAPA DE CONSOLIDALCIÓN.

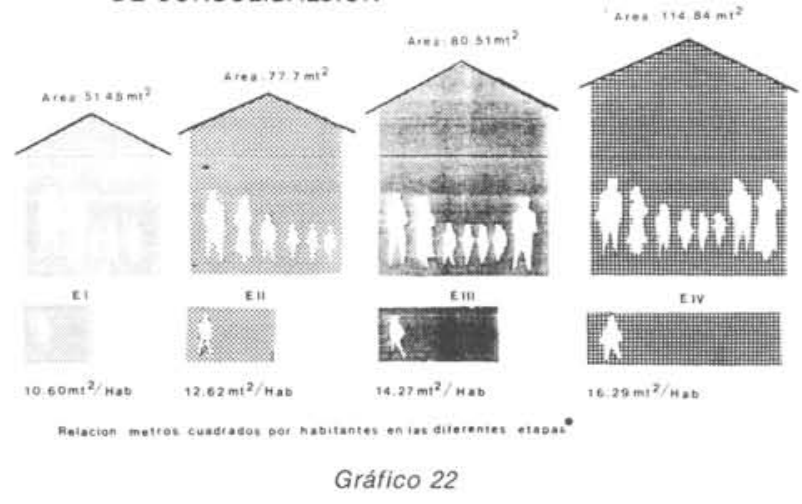

\section{Servicios disponibles}

En este punto haremos referencia solamente a los servicios infraestructurales que brinda el sector oficial y su presencia en las viviendas, y no a las formas de servicio improvisadas para suplir la falta de alguno.
El gráfico 20 muestra cómo el servicio de electricidad está presente desde la primera etapa en un $80 \%$, el de aseo urbano en un $54 \%$, y el de aguas blancas el $36 \%$, mientras que el gas público, el teléfono y las cloacas prácticamente no existen. El porcentaje de viviendas servidas aumenta con la consolidación en todos los casos, llegando a disponer de electricidad, aseo y agua la casi totalidad para la última etapa, y alcanzando un $70 \%$ la dotación de gas público, un $50 \%$ las viviendas conectadas a la red de cloacas y un pobre $17 \%$ con servicio telefónico.

\section{Composición de la vivienda}

En este punto se analizará el tamaño de la vivienda me. dido en número de espacios a través de las etapas de consolidación. Aunque suponemos que las familias, al invadir un terreno, comienzan por tener un solo espacio donde realizan todas las actividades, con excepción de las necesidades fisiológicas para las que construyen un pequeño espacio adicional, observamos los promedios por etapa para concluir a este respecto.

En la primera etapa, a pesar de ser caracterizada por la provisionalidad de los materiales, aparecen diferenciados cuatro espacios (ver planta de VIVIENDA FORMATIVA TIPICA), y va creciendo hasta alcanzar casi los ocho espacios en la última etapa. El baño está separado de la vivienda en la mayoria de los casos de las 3 primeras etapas (El: $98 \%$, Ell: $83 \%$, Elll: $56 \%$ ). En la última etapa ya el $80 \%$ tiene los servicios sanitarios integrados a la vivienda y con todas las piezas sanitarias. Esto está directamente relacionado con la existencia o no de cloacas en el sector donde está ubicada. (Gráfico 21).

\section{Área de la vivienda}

El tamaño de la vivienda crece con el tiempo. La vivienda de producción informal es de crecimiento progresivo. El promedio del área de la vivienda va desde $51,48 \mathrm{~m}^{2}$ en la primera etapa hasta $114,84 \mathrm{~m}^{2}$ en la última etapa. (Gráfico 22).

Resulta interesante relacionar el crecimiento de la vivienda con el aumento del número total de personas que la habitan y que señalábamos anteriormente. A pesar de que ambos crecen, el índice o estándar de metros cuadrados por persona no se mantiene, sino que crece también con ellos, pasando de $10,60 \mathrm{~m}^{2} / \mathrm{hab}$. a $16,29 \mathrm{~m}^{2} / \mathrm{hab}$.

\section{Componentes constructivos}

Esta parte hace referencia a los componentes y sistemas constructivos utilizados. Se consideraron aquí la 
cimentación, la estructura vertical, la estructura de la cubierta y del entrepiso si lo hubiera, y los materiaies y acabados de los cerramientos, piso y cubierta. Estos componentes sirvieron para determinar las cuatro etapas de consolidación física de la vivienda que se han establecido en este trabajo. En el análisis pormenorizado de cada una de las etapas se señalarán los componentes constructivos de las mismas y los niveles de presencia de los mismos, cuya variación deberá estar dentro de los límites establecidos para cada etapa. Como se podrá suponer, esta parte es la base a partir de la cual se hicieron todas las relaciones y cruces de variables.

\section{ASPECTOS DE LA CONSTRUCCIÓN}

\section{Miembros de la familia que construyen}

Aqui se analiza la participación de los miembros que habitan una vivienda en su construcción. El análisis se hace para el momento actual de la vivienda, que contempla un tiempo que abarca hasta un año atrás, para determinar la participación en la construcción en cada etapa, sin mostrar el proceso mismo de la construcción en su totalidad. (Gráfico 23).

De acuerdo al gráfico 23, la participación es mayor en las etapas iniciales (sobre todo en la FORMATIVA), siendo el padre el miembro de la familia o grupo que más aporta en la construcción. La participación va disminuyendo a medida que la vivienda se consolida para ser sustituida por contratación de ayuda externa (albañiles, herreros y hasta contratos totales). Esto es posible en las últimas etapas debido a la mejora que experimentan en su situación económica, a la edad avanzada de los jefes de la casa para ese entonces y a la complejidad de los procedimientos constructivos de las viviendas TERMINADAS (más especializados).

PARTICIPACIÓN DE LA FAMILIA EN LA CONSTRUCCIÓN DE LA VIVIENDA

Padres

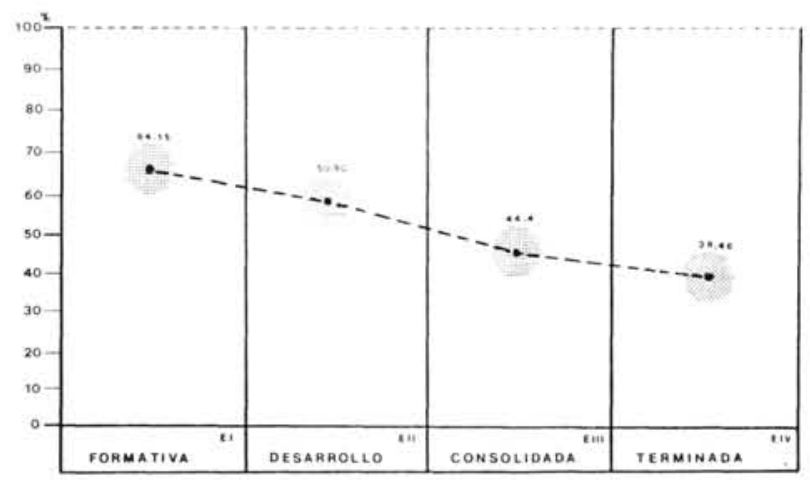

Gráfico 23

\section{Obtención de los materiales}

En general, predomina la compra de los materiales de construcción al detall $(60,39 \%)$, y en muy pocos casos se compran al por mayor $(8,70 \%)$. En la etapa FORMATIVA, donde predominan los materiales de desecho o reciclados, se observan casos en los que los materiales se obtuvieron de otras maneras (de una demolición, donados o extraidos).

\section{ASPECTOS DEL FINANCIAMIENTO}

\section{Tipo de financiamiento}

La casi totalidad de las viviendas encuestadas, sus ampliaciones y mejoras son autofinanciadas por los miembros de la familia (92,75\%), y solamente una pequeña cantidad $(7,25 \%)$ reciben algún tipo de préstamo, incluyendo los de los organismos oficiales (ej.: créditos populares de INAVI) y los de particulares y parientes (Gráfico 24).

TIPO DE FINANCIACIÓN DE LA VIVIENDA

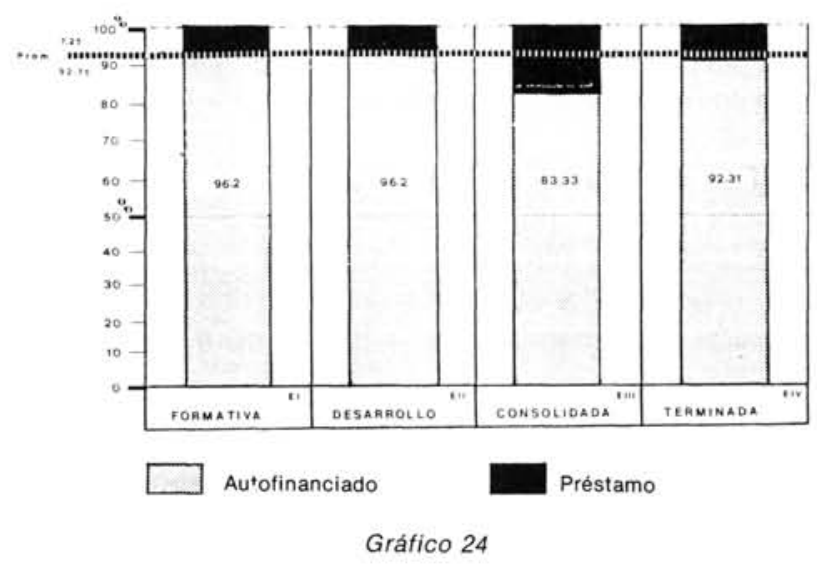

\section{CONCLUSIONES}

La consolidación física de la vivienda es un proceso evolutivo, por lo cual está intimamente relacionada con el paso del tiempo. A más tiempo más consolidación física. Por esta misma razón conserva una relación directa con otras variables relacionadas con el tiempo, como la edad de los miembros de la familia o la edad de la vivienda, y con otras variables indirectamente relacionadas con el tiempo, como el aumento del ingreso familiar, la dotación de servicios públicos, el adquirir la propiedad del terreno o el aumento del tamaño de la vivienda (decimos que conservan una relación indirecta porque de aumentar o mejorar lo harán con el paso del tiempo, aún cuando no estén obligadas, ya que en realidad su variación depende de otros factores). 
En el caso de las primeras, se da una evolución paralela de ambas; pero en el caso de las segundas hay dos grupos: uno que evoluciona independientemente de la consolidación y otro que influye determinantemente en ella.

Sin embargo, una vivienda puede llegar a tener 15 años, como se observa en algunos casos, y aún pertenecer a la ETAPA FORMATIVA, o bien alcanzar la ETAPA TERMINADA en 2 años. Esto obedece al juego combinado de estas variables, cuya influencia concluiremos aqui particularmente para cada una de ellas.

Para aquellos casos en que no se cite explícitamente, las conclusiones están referidas a la vivienda de producción informal y a la ciudad de Maracaibo:

1. La ciudad de Maracaibo está conformada en más de la mitad de sus áreas por barrios o asentamientos no controlados. La mayor parte de las viviendas de los barrios está ubicada en zonas planas, no inundables.

2. Las viviendas de los barrios son producidas de una manera informal, por la ausencia total de la intervención de créditos financieros y de permisos de construcción, y por la baja composición de capital en la construcción (gran inversión de mano de obra y tiempo y baja inversión de capital y tecnología).

3. Las viviendas de los barrios siguen un proceso de transformación en el tiempo hacia su consolidación física, pasando de ser una vivienda precaria o rancho a una vivienda en buenas condiciones, en lo que a construcción se refiere, comparable a una producida por el sector formal de características comparables.

4. En la transformación o línea evolutiva de la vivienda de producción informal se distinguen etapas de consolidación que presentan características similares en toda la ciudad, sin importar la ubicación de la misma.

5. La consolidación física está asociada al aumento del ingreso mensual familiar, es decir, a la mejoria de la situación económica de la familia, aún cuando no se registra un aumento sustancial y la cifra no alcanza al doble del salario mínimo.

6. La situación de ilegalidad en la propiedad del terreno no es un impedimento para el proceso de consolidación, siempre y cuando el terreno sea de propiedad municipal. Sobre terrenos de propiedad privada no se consolida; esta forma de tenencia desaparece con la consolidación.

7. La dotación de servicios públicos es un factor determinante de la consolidación física sólo para algunos de ellos. La ausencia del servicio telefónico, la red de gas y la red de cloacas no influyen en absoluto; pero la dotación de agua y electricidad son determinantes. La segunda de ellas porque en principio parece que hasta no se llega a edificar sin su presencia.

8. El tiempo promedio que tarda una vivienda de producción informal en culminar su consolidación física está alrededor de los 18 años, y los promedios para alcanzar cada una de las etapas son los siguientes:

Etapa I: Vivienda formativa

7,57 años

Etapa II: Vivienda en desarrollo

8,92 años

Etapa III: Vivienda en consolidación

12,06 años

Etapa IV: Vivienda terminada

17,94 años

9. La vivienda de producción informal va creciendo en superficie y cantidad de espacios conforme se va consolidando.

10. El aumento de superficie y cantidad de espacios de la vivienda se realiza en un solo piso. El crecimiento vertical de la vivienda es una excepción en Maracaibo.

11. La construcción de la vivienda de los barrios es autofinanciada por los miembros de la familia que la habitan.

12. La participación de los miembros de la familia en la construcción de la vivienda pasa de la autoconstrucción (en buena medida, aunque no totalmente) en las etapas iniciales a la administración de la obra con la contratación de ayuda externa en las etapas finales; $\sin$ embargo, a lo largo de todas las etapas el proceso es de autogestión.

Esta característica está relacionada con el aumento del ingreso familiar (que permite la contratación) y con la edad del padre para la última etapa (que es el que más participa en la construcción de la vivienda). 


\section{BIBLIOGRAFIA}

(1) ANDRADE, R. y ARAGOT DIAZ, J.; Las formas que asume la producción informal de vivienda en Mérida. Centro de Investigaciones de la vivienda (CINVI); FAULA, Mérida, Venezuela, 1987.

(2) BAZANT, JAN; Vivienda autoconstruida en México (copia parcial). Editorial Trillas, México, 1986.

(3) BAZANT, J. y otros; Investigaciones en autoconstrucción. Memoria de la Primera Reunión Nacional sobre Investigaciones en Autoconstrucción; Consejo Nacional de Ciencia y Tecnologia, México, 1979.

(4) BOLIVAR, T.: Foro sobre vivienda en los barrios. Semina- rio Vivienda 86; Fundación de la Vivienda popular, Caracas, Venezuela, Marzo de 1982.

(5) DE SOTO, H.; La economía informal. Centro de Divulgación de Conocimientos Económicos (CEDICE); Caracas, Vene. zuela, 1986.

(6) LOVERA, A.; MARCANO, L.; De la autoconstrucción a la promoción inmobiliaria. Realidades y proposiciones pa. ra un plan nacional de vivienda. Revista IDEC, Tecnologia y Construcción N.․2, UCV, Caracas, Venezuela, 1986.

(7) MARCANO, E.; ¿Qué soluciones habitacionales? Seminario internacional "Soluciones habitacionales desarrolladas en la población de bajos ingresos en el tercer mundo". FAU, UCV, Caracas, Venezuela, Abril de 1987.

\section{publicaciones del ICCET/CSIC}

La experiencia nacional en construcción industrializada en la última década, aunque no abundante, puede resultar paralizante. Como reacción, este trabajo trata de elaborar y ordenar la información que, pegado al terreno, se ha acumulado durante los sesenta.

Auscultando tendencias avanzadas en otros paises y apoyándose en nuestra realidad cotidiana, el autor de este trabajo apuesta por la industrialización, presintiendo un futuro con pocos puntos en común con lo que en general, hasta bien reciente, se ha conocido como construcción industrializada.

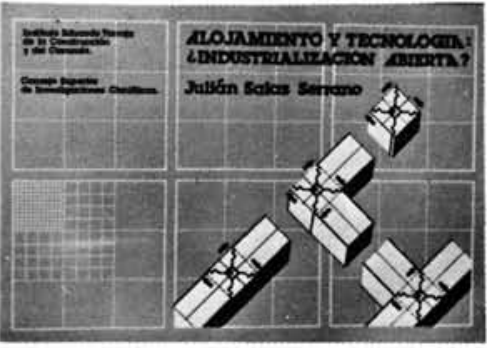

Se abre el trabajo con un prólogo del Profesor Ciribini en el cual, con rigor conceptual y desde su rica experiencia, analiza algunos de los conceptos más polémicos del fenómeno de industrialización del sector construcción. El autor recopila un conjunto de aportaciones de maestros de la arquitectura al lento proceso de evolución tecnológica y conceptual, continuando con un intento de respuesta realista a la interrogante que flota en el sector nacional: ¿réquiem por la industrialización?

Se dedican otros capitulos a revisar lo realizado y a encarar el futuro inmediato: el concepto de componente, su repercusión económica, la dificultad del proyecto a base de productos industriales, la nueva vigencia embrionaria de la construcción por medio de catálogos, los conceptos de flexibilidad e intercambiabilidad desde una óptica práctica... Especial atención dedica este trabajo a la exposición de lo que podiamos llamar nuevos derroteros de la coordinación dimensional, aportando una visión actualizada y pragmática de los enfoques más implantados en Europa.

Las siempre problemáticas interrelaciones entre normativa, calidad e industria se detallan de forma documentada y realista. Finaliza el trabajo con unas reflexiones dirigidas al ámbito empresarial y un esbozo de «reglas de juegon que faciliten al subsector la salida del timpassen actual.

Un volumen encuadernado en rústica, de $24 \times 16,5 \mathrm{~cm}$, compuesto de 160 páginas, con 109 figuras, 19 tablas y 86 referencias bibliográficas. Madrid, junio, 1981 .

Precios: España 1.200 PTAS. Extranjero 19 \$ USA. 